\title{
Tasarım Biçimlerinin Teknik Oluşumuna ve Materyal Kültür Alanının Yapılaşmasına Etki Eden Kültürel Dinamikler
}

\author{
Serhat BAŞTAN*
}

\begin{abstract}
$\ddot{O} Z$
Kent, yaşam mekânı, araç-gereç veya sanat eseri gibi herhangi bir tasarım formunu ortaya koymanın semantik, estetik ve işlevsel yönleri bulunur. Bu yüzden insanın dönüştürdüğ̈̈ maddi varlık alanının tasarımı çok yönlü bir iletişsim süreci olarak ele alınabilir. Tasarım bireysel bir teknik uğraşı, enformasyonel bir girişim, biçimlendirici ve üretken bir eylem gibi görünebilir. Ancak tasarım eylemi tasarlayıcı aktörün yalıtılmış bireysel bir çabası değil bütüncül bir tekno-kültürel paradigmadan yararlanarak kaynaklarını temin ettiği, tabi olduğu kültürel kod ve yordamlardan esinlendiği karmaşık bir süreçtir. Bu ana eksende çalışmamız belli bir türden tasarımı değil ama genel olarak insanın tasarlayıcı eylemini sorgulamaya açacak bir analiz çerçevesi oluşturmayı amaçlamaktadır.
\end{abstract}

Anahtar Kelimeler: Tasarım, enformatif eylem, materyal kültür, kültürel etos, teknokültürel paradigma, toplumsal ekoloji.

Jel Sinıflandırması: D83, L15, O33, O35.

\section{Cultural Dynamics Having Impact On Technical Generation Of Design Forms And Structuring Of Sphere Of Material Culture}

\begin{abstract}
There are semantic, aesthetical and functional aspects of any form of design such as a city, a living space, an equipment or an art object. Therefore, the design of material realm of existence transformed by human beings may be discussed as a communication process. Design may seem to be an individual technical work, an informational attempt, a formative and productive action. However, the action of design is a complicated process that a designer actor procures its resources by utilizing a holistic techno-cultural paradigm, inspired by cultural codes and procedures, upon which s/he is dependent. Design is not a performance of an isolated individual. Given the perspective of the endeavor of the work above, this study aims to compose an analyzing frame to discuss the design effort of human beings, not only in a specific form, but in general.
\end{abstract}

Keywords: Design, informative action, material culture, cultural ethos, techno-cultural paradigm, social ecology.

Jel Classification: D83, L15, O33, O35.

\section{GİRIŞ}

Toplumsal dünyayı çevreleyen ve teknik araç gereçlerde, iş ve yaşam mekânlarında, kentlerde somutlaşan yapay varlık alanı işlevsel, semantik ve estetik boyutları içeren kapsamlı bir kültürel çevirimden doğmuştur. Bu varlık alanı gündelik yaşam gereçlerinin üretiminden kent planlaması ve tasarımına kadar birçok farklı insan eyleminin ürünüdür. Kültürel kaynakların ve yordamların

* Manisa Celal Bayar Üniversitesi, İ.İ.B.F., Kamu Yönetimi Bölümü, serhat.bastan@cbu.edu.tr 
somutlaşmış formlarına bürünmüş, sembolik hatta mitik motifler içinde toplumsal dünyanın dişavurumudur.

İnsanların kullandıkları teknikleri, ürettikleri mekânları ve kentsel alanları, paylaştıkları yaşamları, toplumsal dünyanın bu kültürel nesneler düzlemini "doğa (physis) ve kültür (nomos)", "madde ve idea" gibi klasik karşıtlıklar üzerine kurulu düalist bir modelleme yapmadan betimleyecek bir bilimsel analiz çerçevesi geliştirmek mümkünmüş gibi görünmektedir. Tukidides'ten Platon'a, Machiavelli'den Hobbes'a kadar Batı'nın entelektüel birikiminde gözlenen yaygın bir düalist yanılsamaya göre kültürel anlam ve pratiklerin simgesel nitelikleri salt maddi nitelikler olarak anlaşılmakta; toplumsal kaynakları daha ziyade bedensel arzulara atfedilmekte; rastgele yerine getirilmeleri ise evrensel geçerliliği olan "rasyonel seçimler" adı altında gizemli ve anlaşılmaz kılınmaktadır. Hâlbuki karş1lıklı etkileşen öznelerin olduğu bir evrende, maddi pratiğin türün-ötekileriyle iletişim kurmayı ve onların sembolik nitelikli bilgisine erişmeyi gerekli kıldığını hatırlamak gerekir. Zira insanlar kendilerini verili kültürel düzenler içinde oluştururlar (Sahlins, 2012: 64, 105, 110). O halde materyal kültür alanını yapılaştıran tasarlayıcı imgeleme ve teknik eyleme de salt maddi bir varoluş içindeki gerilimler, tesadüfler ve karşıtlıklar üzerine kurulu özçıkarcı bir toplumsallık yoluyla değil insanın bizzat doğası olan kültürün düzenleyici mekanizmalarının filtreleri arasından geçerek meydana gelmiş olmalıdır.

$\mathrm{Bu}$ önkabulden hareketle çalışmamı, metodolojik gereklilikler ve görselleştirmelerin zorunlulukları saklı kalmak kaydıyla, birinin diğerine öncelendiği hiyerarşik kutuplara bölünmüş herhangi bir düalizme düşmeden tasarımı çevreleyen kültürel dinamikleri modellemeyi; tasarlayıcı imgeleme gücünün aralarında bölüntüsüz ve holistik bir süreklilik bulunduğu öne sürülen kültürün soyut ve materyal görünümlerinin izdüşümünde işleyen iletişimsel bir uğraşı olduğu savını kuramsal bir çerçeveye oturtmayı amaçlamaktadır. Yaklaşımımıza göre materyal bir kültür çevresi oluşturmak üzere yürütülen tasarım etkinliği kültürel anlam sistemleri, teknikleri tasarlamayı mümkün kılan mevcut yapısal-konjonktürel elverişlilikler ve toplumsal ekoloji ${ }^{1}$ tarafindan çerçevelenmiştir. Çalışmanın tezine göre, ne tasarlayıcı aktörlerin yaşamlarının tonu, ahlaki ve estetik biçemi, duygu durumu onların maddi koşullarının yüzeysel bir gölge fenomenidir ne de insanın maddi koşulları mutlak bir soyut kültürel düzenlemenin, bir çeşit kültürizmin arı sonucudur. Tasarım, toplumsal ekoloji ve toplumun belli bir tarihsel dönemdeki tasarım geleneklerine hükmeden teknokültürel paradigma ${ }^{2}$ (Marshall ve Pengelly, 2005: 25-33) aracılığıyla erişilebilen kaynakları yüksek beceri ve enformatif eylemle sembolik, estetik ve işlevsel bir iletişim süreci içinde bir araya getirmeyi amaçlayan bölüntüsüz bir zihinsel işlemler pratiği olarak kavramlaştııılmalıdır. 


\section{KÜLTÜR, TEKNIK VE TASARIM KAVRAMLARI ARASINDAKİ İLIŞKİ}

\section{A. Teknik ve Teknoloji Kavramlarının İçeriği}

Teknoloji terimi pratik becerilere ilişkin sistematik bir çalışmayı veya etüdü, beceriyi betimlemek için kullanılır. Terimin kökeni sanat veya zanaat manasina gelen Yunanca tekhne kelimesine dayanır. "Sanat ve zanaat bilgisi" olarak tercüme edebileceğimiz kavram bilim ve bilim adamına ilişkin güncel anlamdaki değişimle birlikte modern kullanımda zanaatın ima ettiği yarar boyutunu öne çıkararak bilgi (ve bilim) ile onun pratik uygulaması (teknoloji) arasındaki bildik ayrıma maruz kalmış (Williams, 1983: 315), sanat terimi ise Rönesans'tan XIX. yüzyıla kadar geçen süre boyunca zanaat kavramından koparak kültürel hayal gücü ve yaratıcılığ 1 kategorilendiren salt estetiğe indirgenmiş bir muhteva kazanmıştır. Etimolojik açıdan bütün bu terimler (sanat, zanaat, teknoloji, teknik) kültürel olarak insan eli ile üretilmiş, yapay, elişi (artefakt) manasında (İngilizcede art-artificial, Almancada kunst-künstlich, Türkçede Arapça kökenli olarak sunizanaat/sınaat/sanat/sanayi ilişkisi gibi) akrabadır. Diğer taraftan nesnenin pratik inşası veya nesneleştirilmiş süreçler üzerinde bilimsel olarak rasyonelleştirilmiş bir kullanım manasında sıfat olarak teknik (technical) ile sıklıkla aynı manada kullanılan ancak "-loji" sonekinden dolayı bilgiye dayalı sistemli ele alış tarzı anlamına da gelen teknolojik (technological) terimleri arasında semantik bir karışıklık söz konusudur. Teknolojik terimi belli bir uygulamadan farklı olarak üretimdeki tüm yaşamsal, temel sistemleri de işaret eder. Dolayısıyla hem bu iki terim (technical-technological) hem de "araç ve yöntemlerin genel bir sistemi" manasındaki teknoloji (technology) terimleri arasında ince ayrımlar bulunur (Williams, 1983: 315; Habermas, 1993: 75).

Bilgi ile ilişkisi bakımından da "teknik" ile "teknoloji" terimlerinin muhtelif disiplinler içinde farklı biçimlerde kullanıldıkları görülmektedir: Sözgelimi bu terimler sosyolojik ve iktisadi akademik okumalarda farklı tarihsel olgu ve dönemlerle eşleştirilmektedir. Bilgi sosyolojisinde teknik bilgi insanın (1) "anlam verme" (semantik) ve (2) "estetik" ile birlikte (3) "teknik kullanma" (işlev) olarak ifade edilebilecek kültürel antropolojik determinasyona dayalı merkezi bir olguyu ifade etmektedir. Bu perspektife göre teknik olanın bilgisi insanlık tarihiyle başattır. Ateş yakma tekniğinde olduğu gibi insanların yaptıkları her işin bir yön ve yöntemini oluşturur. Ellerindeki malzemenin veya araç gereçlerin kullanımını gösterir. Teknolojik bilgi ise özel bir teknik bilgi biçimi olarak sanayi devrimi ile eşlenir. Dönüşlü olarak sanayi hareketi teknolojiyi, teknoloji de sanayii üretip geliştirmiştir (Aydın, 2013: 73-74). Modern antropoloji ise bu iki kavram arasında tarihsel çağ tipolojilerini temel alan ve sözgelimi sanayi devrimini teknolojik bilgi ve neolitik devrimi ise teknik bilgi ile eşleyen bir tasnif yapmaz. "Paleolitik veya neolitik teknolojiler"den, tekniklerden, alet çantalarından ya da alet takımlarından söz eder (Güvenç, 1984: 169-174). Disipliner kavramlaştırma farklılıkları disiplinlerin özgül çözümleme gerekliliklerine göre işlemsel olmak üzere yapılaşmışırı ve bu farklılıklar göz ardı edilerek şöyle söylenebilir: Hem teknik 
kavramının hem de onun teknoloji, teknolojik gibi türevlerinin kültürel evrensellerden ve özgün tarihsel kaynaklardan beslenen çoklu veçheleri bulunur. Teknolojiye ilişkin olgular düşünen, bilen insanın (homo sapiens sapines) alet yapma yetkinliğine gönderme yapar. Bu yetkinliği Henri Bergson, Max Scheler ve Hannah Arendt gibi düşünürler insanın teknikler geliştirerek çevrelerini kontrol edebilme, yapay bir çevre inşa edebilme becerisine atfen "homo faber" (araç yapan insan) kavramiyla nitelerler. Arendt'e (1998: 121) göre homo faberler pratik ile düşünce arasında bağlantı kuran ustalar, zanaatçılardır: "Hiçbir iş aletsiz gerçekleştirilemez ve homo faberin doğuşu ile nesnelerin insan yapımı dünyasının ortaya çıkışı, araç gereçlerin keşfiyle aynı döneme denk gelir”. Homo faberlerin (pratik ile düşünce arasında bağlantı kuran sanatçının, zanaatçının, ustanın, teknisyenin veya mühendisin) yapay nesneler tasarlayabildiği bir toplumsal dünya artık kültürel uyarlamaya dayalı yapay bir materyal kültür alanı içinde örgütlenir. $\mathrm{Bu}$ materyal kültür alanını tasarlayan homo faberlerin imgeleme gücünün kaynaklarını çözümlemek için geleneksel zanaattan elektronik devrime, kentsel mekânların üretimi ve mimariden resim, sinema gibi incelikli entelektüel uğraşılara kadar oldukça geniş bir gamı teknik kavramının çerçevelediği bir şema altında toplamak mümkündür. Bu ölçekte ele alındığında teknik kavramı, her bir uğraşının niteliğine göre birleşim oranları farklı olsa da işlevsel, semantik ve estetik formları nesneye aktaran homo faberin artefakt bir kültür alanı üretmek üzere ortaya koyduğu bütün tasavvurlarını, bilgi, araç, yöntem ve uygulamalarını ima eder.

\section{B. Kültürel Anlam Sistemleri ve Kültür Örüntüleri ile Tekniklerin İlişsisi}

Uzun zaman kültür kavramını ana hatlarıyla "bir toplumsal bütünü nitelendiren maddi ve düşünsel teknikler, inançlar ve davranış kurallarının tutarlı bir bütünü” (Duverger, t.y.; 73) olarak tanımlama eğilimi literatürde yaygın kabul görmüştür. Böylesine yüksek oranda bir tutarlılık, istikrar ve bütünlük varsayımı yerini bugün giderek sosyal sistemlerin soyut ve maddi yordamlarındaki içsel örüntü benzerliklerinin tekrarlı görünümlerinden türeyen karmaşıklıkları, süreklilik, kırılma ve başkalaşmaları kavramlaştırmayı yeğleyen bir yaklaşıma bırakmaya başlamıştır (Sarıbay, Öğün, 2013). Buna göre birey veya grup halinde insan davranışına ilişkin hemen her şey kültüreldir ya da insana dair kültürel olmayan çok az şey vardır. Zira insanın teknik, düşünsel veya davranışsal herhangi bir biçimde ortaya koyduğu her ürüne şekil veren kültürel yordam ve kılavuzlar toplumsal dünyaya içkin hemen her an ve her yerde işler durumdadır. Bu normatif şemaların, plan, tarife ve yönergelerin yönlendirmesini takip etmediğinde insan davranışları anlamsız eylemlerin ve patlak veren duyguların kaosundan oluşan tamamıla biçimsiz devinimlerden ibaret olurdu (Geertz, 1973: 46). Buradan hareketle kültür altta yatan bir takım süreklilikler aracılığıyla insan davranışlarını ve bu davranışların ortaya koyduğu nesnel ürünleri az çok tutarlı bir bütünlük içinde organize etmeye çalı̧̧an normatif bir düzenleyici, insan eylemlerine biçim 
kazandıran ama başkalaşmalara (alteration) hatta kırılmalara da açık dinamik ve karmaşık bir semantik sistem olarak tasavvur edilebilir.

Kültürler toplumsal aktörler arası zımnî eşgüdümleme ve uzlaşımlar aracılığıyla teamül, değer ve anlam şemalarının tekrarlı üretimine dayanırlar; süreklilik zemininde dinamik ve karmaşık norm ağlarına yol açarlar. Bu manada toplumsal dünyanın gelişigüzelliğine biçim veren az çok istikrarlı bir anlam sistemi içinde örgütlenirler. Bütün dinamik ve karmaşık sistemlerde olduğu gibi herhangi bir kültürel anlam sisteminde de doğrusalsızlık (nonlinearity), özörgütlenme (selforganization), özbenzeşim (self-similarity), nispi istikrarsızlık gibi özellikler gözlenir. Bu tarz sistemler deterministik neden-sonuç mekaniğine tabi değildirler. Küçük ve benzer başlangıçlardan, kaynak ve etkilerden çoğalan ve başkalaşan zengin örüntüler üretme eğilimindedirler. İstikrarsızlık veya kriz zamanlarında dağılma, kendini yenileme ve önceki kısmi bileşenlerine dayanarak yeniden yapılanma, konjonktürel koşullara göre orijinal biçimler üretme yönünde evrimleşirler (Dimitrov ve Woog, 1997: 502, Kiel, 2015). Hiçbir sistemin evriminin hiçlik üzerine işlemediği gibi kültürel anlam sistemlerinin evrimi de hiçlik üzerine işlemez. Niklas Luhmann'ın (2000: 107-108) ifadesi ile bu sistemler kendilerini belirlerler ve bunu kendi kendilerini üreten yapıları aracılığıyla gerçekleştirirler. Yapıların aynı elemanlarla rekonfigürasyonu ve kodlanması kültür örüntülerini ve bu örüntülerde izlenen süreklilikleri üretir. Kültür örüntüleri herhangi bir bireyin bakış açısından, o birey daha var olmadan önce büyük ölçüde topluluk tarafından belirlenmiş anlaml1 simgelerin örgütlenmesi yoluyla düzenlenmiş dizgelerdir (Geertz, 1973: 45-46). Bu dizgeler aracıllı̆ıyla kültürler belirli kalıpları eşzamanlı veya farklı dönemlerde aynı toplumda aperiyodik olarak tekrar eder niteliktedir. Dolayısıyla kültürler yarı-istikrarlı bir özellik arz ederler.

Yine aynı yapılar içinden doğan kırılmalar, enformasyonel orijinallikler ve başkalaşmalar ise kültür örüntülerinde değişimlere yol açarlar. Başka bir ifadeyle kültürel değişimler, kültürlerin kendi anlam şemalarının kalıtlarına dayanarak kendileri içindeki dönüşümlerle gerçekleşirler. Örneğin Fransız Devrimi'nin Fransız bayrağında cisimleşen (pekçok Avrupa bayrağında olduğu gibi) özgürlükeşitlik-kardeşlik (liberté-égalite-fraternité) mitosu tarihsel egemen Katolik kültürünün teslis (Baba-Oğul-Ruh-ül Kudüs) biçiminde tanımlanan eski kültürel anlam formunun kodlarını izleyerek seküler düzlemde yeniden üretilmiştir (Sarıbay ve Öğün, 2013: 88). Fransız folklorunun efsanevi genç kadın idolü Marianna'ın Delacroix'nın Fransız Devrimi'ni betimleyen "Halka Önderlik Eden Özgürlük" adlı tablosundaki sembolizasyonu (Batur, 2012: 18) mitolojik (Marianna), dinsel (teslis) ve modern (devrim hareketi) örüntüleri sentezleyen tipik bir kültürel kodlamadır. Görülüyor ki, kültürel değişim tarihsel kaynaklarındaki mitik form ve işlevleri koruyarak estetiğini ve semantiğini yeni durumlara uyarlamaktadır.

Kültür örüntülerinin işlevlerinin, insanın maruz kaldığı karmaşık doğal ve toplumsal fenomenlere anlaşılırlık kazandırma, onları basitleştirerek anlamları ve değerleri hakkında kolektif teamüller oluşturma, dilleştirme, simgeleştirme ve doğal/toplumsal çevreyi denetleme olduğu söylenebilir. Bunun bir bedeli olarak 
semantik bir düzen kurmaya yönelik her soyutlama, basitleştirme ve dilleştirme süreci insanın algıladığı gerçekliği temsil yoluyla filtreleyerek veya perdeleyerek kültürel bir hakikat kavrayışı içinde dondurur. Bu durumun nomolojik gerçeklikle kültürel anlam sistemleri arasında bir farka veya gerilime yol açma ihtimali yüksektir. Diğer yandan toplumsal ekolojinin ve yaşamın fiili olguları, er geç görgül olarak kültürel repertuarda birikirler ve katılaşmış kültürel anlam sistemlerini metafizik esrarlarından sıyırarak gerçekliğin akışıyla uyumlanmaya zorlarlar. Malinowski'ye (2000: 25) göre insan sadece bilgisinin ve rasyonel yöntemlerinin yetersiz kaldığını gördüğünde çözüm olarak büyüsel ve mitik nitelikli bir kültürel anlam metafiziği üretme eğilimindedir. Esas olarak rasyonel düzeyde denetleyebildiğini pratikte önceler. Doğru inşa edilmezse bir teknenin yüzemeyeceğini, soğukkanlılık gösterilmezse bir savaşın kazanılamayacağını iyi bilir. Dolayısıyla eğer isabetli teknik çözümlerle inşa edilmiş belli bir kültürel materyal alanı varsa, bu alan uzun ve esnek bir kültürel kazanımlar sürecinin konjonktürel bir görünümü olarak ortaya çıkmıştır. Oysa nomolojik tekniğin ve metafiziğin iç içe geçtiği evreler uygarlık tarihinin ağırlıklı kısmına hakim olmuştur. Çeşitli uyumsuz ve tamamlanmamış algılayışların, kavrayışların ve soyutlamaların bir aradalığını yansıtan bu uzun zaman dilimleri "paradigma öncesi” olarak adlandırılan (Kuhn, 2008: 81-95) evrelerdeki kültürel örüntülerin irrasyonel, tutarsız ve istikrarsız biçimlenmeleri şeklinde tezahür etmiştir. Binlerce yıl boyunca içinde kültürlerin anlam sistemlerinin ayıklanma ve uyarlanmasıyla dönüşmesi sayesinde doğal sistemlerin akış ve ilkeleriyle tutarlılık içinde isabetli tekniklere elverişli toplumsal konjonktürlerin ortaya çıkması istisnadır. Antik Sümer, Babil veya Mısır'ın hidrolik uygarlık sistemleri, Geleneksel Çin'in teknik başarıları, Klasik Grek aydınlanması, Buhara, Semerkant ve Endülüs merkezli İslam Yükselişi ve Rönesans kültürel anlam sistemlerinin tutarlı paradigma oluşturan bir düzlemde bilimleşmeye ve teknikleşmeye başladığı sözkonusu özel konjonktürel dönemlerdendir. Ernst Cassirer (2011: 39-46) Rönesans'1 takip eden modern zamanlarda ortaya çıkan bilimsel düşünce tarzının şeylerin mekânsal nedensellik içinde temas ve benzerliğine dayalı, birlik içinde bir kozmoloji üreten mitik düşünce tarzını (örneğin Babil geleneğinden gelen astrolojiyi) zamansal nedenselliğe dayalı tekil olguların yasa temelli birliğine dönüştürerek (örneğin modern astronomi) bu gelişmeyi sağladığını ileri sürer. Görünen o ki, kültür örüntüleri ile teknik isabetlilik arasındaki mütekabiliyetin artış gösterdiği bu süreç boyunca bir taraftan kültürel anlam sistemleri doğal ve toplumsal denetim biçimlerini kavrayan zihinsel kozmolojilere dönüşerek rasyonelleşirken (modern bilimin ortaya çıkışı) diğer taraftan teknik yoluyla kültürün artefakt alanları doğal ve toplumsal güçlerin duyarlılıkları altında aynı bağlamdaki zihinsel tasarımlardan görgül dünyaya holistik bir yapıda eşanlı olarak yansımıştır.

\section{C.Materyal Kültür ve Teknik Tasarımın Kültürel Kaynakları}

Materyal kültür, grup yaşamının organize edildiği görülebilir bir insan ortamı oluşturmak üzere insanların çevrelerindeki doğal kaynaklardan türettiği ve 
farklılaştırdığı nesnelerden oluşturulmuş kültür olarak tanımlanır (Epstein, 2008: 172). Başka bir ifadeyle materyal kültür kavramı insanların tekniklerle, teknolojilerle dönüştürdükleri varlık alanını, fiziksel çevrelerini işaret eder. Ancak bu alan katıksız olarak fiziksel nesnelerden ibaret değildir. Görgül gerçeklik açısından düşünceler, fiiller ve artefaktlar iç içe geçmiştir. Öyle ki zihnî, fiilî ve maddi görünümleri birbirinden ayrıştırmak son derece zordur (Rosengren, 1994: 2).

Phillip Kottak'a (2002: 263) göre insanlar yaşadıkları çevrelerin önlerine getirdiği sorunlarla baş edebilmek için gerek biyolojik özellikleri gerekse (kültürün bir boyutuyla) kazanılmış/öğrenilmiş davranış örüntüleriyle iki yönlü bir uyarlanma geliştirmişlerdir. Bu uyarlanma çevre ile istikrarlı bir ilişki kurulması arayışı yoluyla olur. Çevresel değişimle yüz yüze geldiğinde insanlar yeni bazı baş etme mekanizmaları deneme yoluna başvururlar. Başka bir deyişle çevresel zorluklar ve değişimler yeni uyarlanma arayışlarına, dolayısıyla teknik çözüm ve çeşitlilikte doğurganlığa yol açarlar. Bu eksende Kottak'a göre insanoğlunun kültürel uyarlanması sürecinde teknik manada görülen temel yönelimler boyunca;

1. Araç ve gereçlere bağımlılık artmış,

2. Araç ve gereçlerin sayısında artış olmuş,

3. Araçlar çeşitlenmiş ve işlevsel olarak farklılaşmış; daha özgül işler için tasarlanır hale gelmiştir. Yapay nesneler inşa etme becerisi, araç ve gereç yapmak üzere araç ve gereçler üretmek ve bunları tekrar araç ve gereçler üzerinde uyarlamak suretiyle sonsuz çeşitlilikte kültürel materyal bir dünya imal etmiştir. Ancak kültürün materyal dünyasına mekanik bir çeşit "çevresel etki-kültürel tepki" ilişkisinin sonucu biçiminde yaklaşmak, konuya fazlasıyla determinist ve yüzeysel bir perspektifle bakmak olarak eleştirilmiştir. Duverger (t.y.: 53, 64) ekolojinin toplumların yazgılarını kör bir kabalıkla çizdiğini, insanın doğanın ellerine bırakılmış bir kil parçasından başka bir şey olmadığını öne süren bu tarz görüşleri ekolojik determinizm olarak tanımlar. Ekolojik determinizmin karşısında ise “meydan okuma kuramı” bulunur. Örneğin Arnold Toynbee, insanın ortamıyla olan ilişkilerinin, yalnızca ortamın zorunlu kıldığ 1 doğal çizgide ilerlemediği, aksine ortama tepki gösterme yoluyla geliştiği düşüncesini ortaya atar. Buna göre kolaylık uygarlığın zararınadır ve gelişme ortamdan gelen düşmanlıkla uyarılır. Duverger'ye göre bu görüş de en az ekolojik determinizm kadar tartışmaya açıktır. Duverger, bu iki yaklaşımın yerine, coğrafyanın tuvali verdiği, üstünü insanın doldurduğu, dolayısıyla olabilirlikler arasından yapılan seçimler üzerine kurulu bir kültürel "ortak tasarım" kavrayışı önerir. Örtük olarak burada insanın çevresini dönüştürme ilişkilerinde çevreden gelen elverişliliklere ve bu elverişlilikleri değerlendirmeyi tercih eden toplumsal olumsallıklara dayalı bir kavramlaştırma yapılır ve bu yaklaşım bizim buradaki çözümleme şemamızla da uyumludur.

Sosyal teorinin önemli kavramlarından biri olan olumsallık (contingency) belli seçenekler ile sınırlandırılmış kısmi zorunsuzluk anlamına gelir. Luhmann olumsallık terimini "seçime bağlı olma" anlamında kullanır. Bir olgu bir seçime rağmen yine de bazı ihtimallerin kaldığı diğer ihtimaller arasından bir seçim olarak 
görüldüğünde olumsaldır. Başka bir deyişle seçim yapmaya zorlanmak olumsallık demektir çünkü her zaman farklı seçimler yapılabilecektir. Etkileşim içine giren her aktör etkileşime kendi olumsallığını taşıyacağından olumsallıkların bir karşılıklılığ sözkonusu olacaktır. Bu duruma da çifte olumsallık (double contingency) denir. Luhmann'a göre çifte olumsallık kavramı (i) başka türlü olma ihtimali dışında, belirli (yaşanılan, beklenen, anımsanan, hayali kurulan) bir şeyi (ii) muhtemel çeşitlilikler ufku içindeki nesneleri ve sonuç itibariyle, (iii) bireyin eyleminin tesadüfî değil başka aktöre bağlı olduğunu, fakat (iv) birçok alternatif arasından bir seçimi gerektirdiğini anlatır. Toplumsal etkileşimlerin çifte olumsallığı "birey ve diğerinin karşılıklı bağımlılığının değil birbirleriyle ilişki içinde kendi seçimlerini yapan en azından iki özerk sistemin karşılaşmasının sonucudur."(Tatlıcan, 2011: 197; Ritzer, 2012: 194). Materyal kültür alanının oluşumuna ilişkin süreçleri de bu etkenden bağımsız olarak düşünmeyi gerektiren bir neden yoktur. Tasarım ve tekniklerin varoluş tarzı önemli ölçüde olumsallıkları içerimleyen toplumsal etkileşim dinamikleriyle birlikte ortak tasavvurların, kabullerin ve normatif olarak belirlenmiş kültürel kodların çerçevelediği bir sınır içinde vuku bulacaktır. Buna göre insan kültürünün materyal dünyayı dönüştürmesi toplumsal ekolojinin elverişliliklerinin çerçevesine bağımlı olduğu kadar, toplumsal aktörlerin yüksek oranda düşünsel soyutlayıcı uğraşılarının esnek işleyişine ve karşılıklı olumsal etkileşimlerine, kültürel anlam ve normlarca kuşatılmış formel çerçevelere de tabidir. Dolayısıyla materyal düzenlemelerin salt fiziksel, nomolojik işlevsel gereklilikleri değil materyal düzenlemelere sınırlar koyan, onları estetize eden, tasarım eylemlerine yön veren ve materyal kültür varlıklarının anlamını yorumlamada kullanılan toplumsal bilgiler, görüşler ve değerler de kendi figürlerini çizerek materyal kültürü nüfuzu altına alacaktır.

\section{TEKNIKLLERIN TASARIMININ ILLETIŞIMSSEL KARAKTERI A.Kültürün ve Teknik Tasarımın Enformasyonel Boyutu}

Everett Rogers (1983: 12) teknoloji kavramını "neden-sonuç ilişkileri çerçevesinde arzu edilen belli bir çıktıyı elde etmek üzere belirsizliği azaltan araçsal bir eylem için geliştirilmiş tasarım” olarak tanımlar. Rogers'ın tanımında "belirsizliği azaltan herhangi bir araçsal eylem" ifadesi enformasyon kullanımınıyla, "tasarım" ise düzenleme, form verme işleviyle eşlenir. Shannon ve Weaver'ın (1948: 379-423) İletişimin Matematiksel Teorisi gibi enformasyon teorisi üzerine kurulan iletişim çalışmalarında enformasyon iletişim sistemlerindeki gelişigüzelliğin artma eğilimine karşı iletinin korunabilen ve aktarılabilen formu ve miktarı olarak ele alınır. Dennis McQuail (1984: 43) enformasyon kavramının temelinin, doğanın bizim kurduğumuz düzeni azaltmak ve anlamlı olanı bozmak eğilimine karşı sürekli olarak verdiğimiz koruyucu ve düzenleyici mücadeleyle bağlantılı olduğunu öne sürer. Doğa bizim teleolojik yönelimlerimiz açısından belirsizliği teşvik ederken -ki, buna dağınım (entropi) diyoruz- enformasyon bu belirsizliği azaltan bir işleve sahiptir. Norbert Weiner (1989: 21) da enformasyon teorisi ile yakın irtibatı olan sibernetik sistemler teorisinde "düzensizlik ile 
dağınım" ve "düzen ile enformasyon" arasında bir eşleme yaparak dağınımın düzensizliğin ölçüsünü, bir iletiler seti tarafından taşınan enformasyonun da düzenliliğin ölçüsünü verdiğini gösterir. Diğer yandan Abraham Moles (1995: 8791) enformasyonu iletinin alıcısının çevresine kattığı yeniliğin ölçüsü olarak tanımlar. Ancak bu yenilik kısmen orijinal kısmen de kavranabilecek derecede öngörülebilir bir formda olmalıdır. Bunun için enformasyonun yararlanılabilir bir kültürel kod sisteminin açtığı yolu izlemesi gerekir ki keyfi seçimlerden türemiş anlaşılamaz bir ileti seti oluşturmasın.

$\mathrm{Bu}$ kavramlaştırmalardan hareketle teknik bir düzenleme yapmak, nesneye enformasyon yüklenmesini; bu yolla onun unsurlarının organize edilmesini, ona anlaşılabilir bir "form" kazandırılmasını gerektirir. Bu perspektife göre enformasyon, fizik nesneye onun materyal özünü dönüştürerek işlevsel, semantik ve estetik açılardan form kazandırmanın başat yönünü oluşturur. Böyle bir nesne Weiner'in (1989: 34-41) ifadesiyle evrenin genel ssısal ölümüne, dağınıma direnen azaltılmış bir dağınım (artırılmış bir enformasyon) odacığı veya adacığıdır. Bu manada artefakt nesneler, tıpkı canlı organizmalar gibi bölgesel ve geçici olarak dağınımın kozmolojik işleyişteki artış eğilimine karşı direnç gösterirler. Teleolojik ve enformasyonel karakter sergilerler.

Rogers'a (1983: 12) göre esasen tekil düzeyde herhangi bir teknolojik ürünün veya tekniğin kullanımı; (i) fiziksel bir varlık, materyal nesne (bilişim terimiyle donanım) ve (ii) bu nesnenin kullanıma sokulması için zihinsel etkinlik/enformatif destek (bilişim terimiyle yazılım) olmak üzere iki bileşeni gerektirir. Rogers ikinci bileşeni enformasyon olgusu ile eşler. Rogers'a göre teknolojinin toplumsal yönü onun mekaniğinden veya teçhizatından genellikle daha az görünür durumdadır. Çoğunlukla sağduyu bilgisi teknolojiyi donanımsal terimlerle tanımlama eğilimindedir. Diğer yandan enformasyon, teknolojilerin başlıca toplumsal veçhesini oluşturur ve hatta bazı durumlarda teknoloji tamamıyla enformasyondan da ibaret olabilir. Bir haber olayını, medya içeriğini veya yazılım kodunu buna örnek olarak verebiliriz. Konuya böyle yaklaşıldığında primitif veya karmaşık, geleneksel veya endüstriyel herhangi bir teknik nesnenin kaçınılmaz olarak zihinsel bir kullanım planına göre enformasyon yüklenerek biçimlendirildiği bir tasarım pratiğinin sözkonusu olduğu söylenebilir. Bu argümana göre tasarlama nesneyi biçimlendirecek enformasyonu nesneye uygulama işidir. Tasarımcı nesnede tanımlanabilir bir değişiklik ortaya koymak için onun materyal özüne enformasyon yükler. Bu enformasyonun kodları ise tasarımcının yaşadığı kültürün semantik ve estetik kaynaklarından gelir. Bu eksende geleneksel zanaattan ileri bilişim sistemlerine kadar herhangi bir teknik uygulamanın bir yönü somut bir nesneyi, teçhizatı gösterirken bu uygulamayı işlevsel hale getiren kodlayıcı bir zihinsel imgeleme sürecinin sonuçlarının da bu nesnede cisimleşmesi sözkonusudur. Dolayısıyla tasarım, kültürel bir artalanı kullanan zihinsel imgelemenin doğal varlığa, bu varlığın tabi olduğu entropik gelişigüzelliğe eğimli yapısına rağmen, beşerî taleplere uygun bir düzenleme yapması, ona enformasyon 
kullanımı yoluyla form vermesidir. Bu durum ise tasarım olgusunu özü itibariyle kaynağında kültürel yordamlar bulunan bir iletişim meselesi haline getirir.

$\mathrm{Bu}$ eksende tasarlayıcı aktörün etrafındaki gelişigüzelliği teleolojik bir disiplin altına alarak anlaşılabilir bir örüntüler dünyası inşa etmesi dolaylı olarak kültürün dar manada materyal dünya ve daha geniş manada da toplumsal etkileşim sistemleri üzerinde negentropik bir etki uygulaması demektir. Bu bağlamda kültür, enformasyon ve dağınım olguları arasında doğrudan bir ilişki vardır. Lévi-Strauss (2013: 104-110) bu ilişkiyi karmaşık uygar toplumların devingenlikleri nedeniyle daha çok dağınım veya düzensizlik üretmesi (artan entropi) ve kültürün de bu durumu düzene sokan, regüle edici bir işlev görmesi (artan enformasyon) düzleminde yorumlar. Ekolojik tükenme, iktisadi çelişkiler ve politik çatışmalar gibi olgular bu toplumlar açısından dağınım üretici etkenlerdir. Diğer yandan gerek yönetsel olguları (üretim süreçleri, yerleşim planları, dağıtım kanalları, paylaşım kararları gibi) ve toplumsal ekolojinin maddi koşullarını (toplumları çevreleyen iklim, yararlanılabilir doğal kaynaklar, coğrafi yerleşim gibi) materyal kültür alanı içinde denetim altına alan gerekse sembolik toplumsal etkileşimlerin değerler şebekesini (anlam şemalarını) örüntüleyen normlar, yaptırım ve yükümlülükler kültürün düzen üretici araçlarıdır. Böyle bir normatif çerçeve, insanlar arasındaki sembolik düzenlemelere olduğu kadar materyal kültür alanının insanların toplumsal dünyalarını kuşatarak biçimlendirmesine de birlikte tümleşik olarak aracılık eder. Materyal kültür alanının oluşumunda iktisadi veya teknik gelişmelere bir uyarlama olarak yayılan değer temelli kültürel uzlaşımlar, dağınım üretici etkenlerin neden olduğu toplumsal dönüşümlerden kaynaklanan gerilimleri normatif olarak telafi eder. Bu perspektife göre anomi, yabancılaşma gibi kültürel teorinin önemli kavramları muhtemelen bu telafi edici fonksiyonun yitimine veya zayıflamasına; en azından yerleşmemiş bir değerler çerçevesinin yaşandığı büyük toplumsal dönüşümler (sanayi devrimi, büyük savaşlar, çekirdek teknolojilerde yaşanan hızlı gelişme gibi) boyunca meydana gelen geçişlerde bir çeşit "geçici toplumsal dağınım" durumunun gözlendiğine işaret ediyor olabilir.

\section{B.Bir İletişim Etkinliği Olarak Tasarım}

Yukarıdaki çözümlemeden çıkan sonuç bizi hangi sofistik düzeyde olursa olsun teknik olguların ve tasarımların enformasyonel özellikler taşıdığı, enformasyonun ise üretildiği kültürün normatif kaynaklarından geldiği; dolayısıyla soyut kültür ile materyal kültür alanları arasında hiyerarşik veya düalistik bir konumlanma değil monolitik ve bölüntüsüz bir tümlük bulunduğu önkabulüne götürür. Bu önkabulden hareketle çalışmamızda sergilediğimiz yaklaşım aşağıdaki gibi görselleştirilebilir: 
Şekil 1. Tasarım Biçimlerinin Oluşumunda Rol Alan Kültürel Ve Çevresel Etkenler

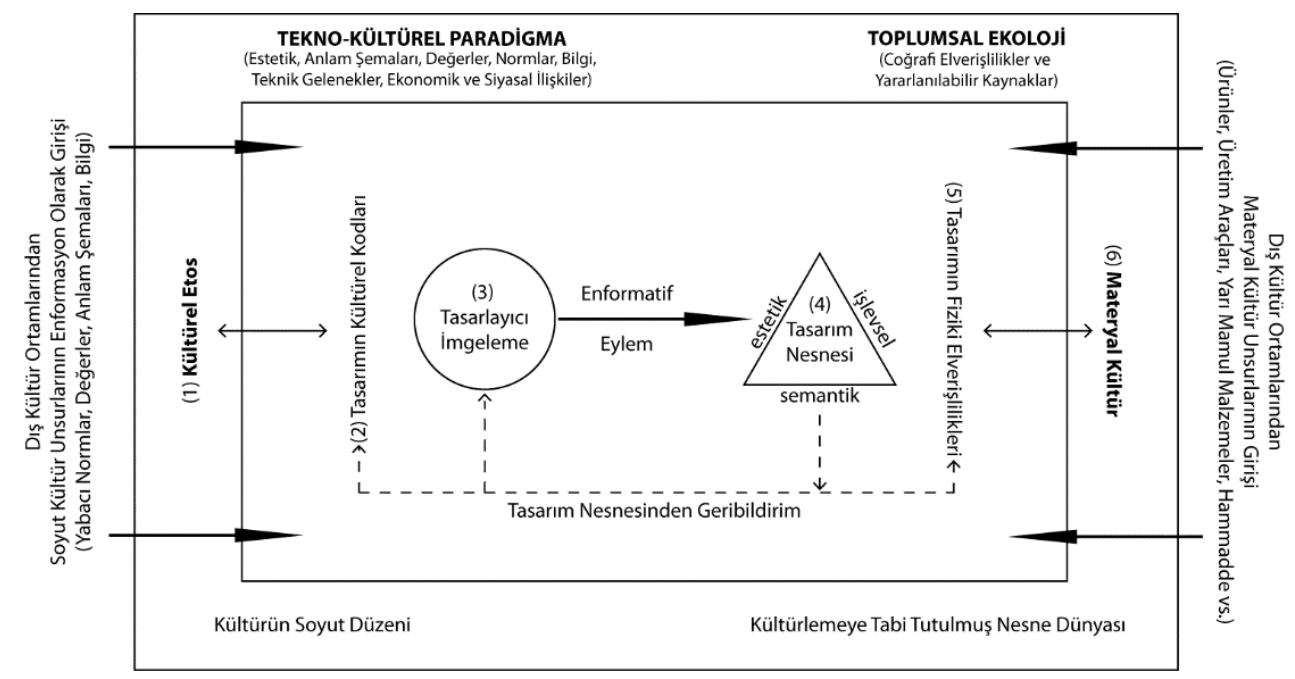

Şekil 1, (1) kültürel etos, (2) tasarımın kültürel kodları, (3) tasarlayıc1 imgeleme, (4) tasarım nesnesi, (5) tasarımın fiziki elverişlilikleri ile (6) materyal kültür arasında integral bir yapı olduğunu; bu yapının tasarım nesnesine estetik, semantik ve işlevsel formlarda yansıdığını ve tekno-kültürel bir paradigma ile toplumsal ekoloji tarafindan kuşatıldığını betimler. $\mathrm{Bu}$ yapının bileşenlerini birbirine şeklin solundan sağına sembolik, semantik etkileşim bağlar ki bu yönüyle enformasyonel/iletişimsel bir ilişki söz konusudur. Şeklin sağ tarafından ise kültürün fiziksel dünyasının biçimlendirilmesine yönelik materyal varlık akışı (hammadde kullanımı, üretim pratikleri vs.) gerçekleşir. Tasarım bu iki boyutun düşümdeştiği bir zihinsel muhakeme alanında meydana gelir. Şeklin kültürün soyut düzenini ve kültürlemeye tabi tutulmuş nesne dünyasını düalist bir şema içinde göstermesi buradaki metodolojik görselleştirme zorunluluğundan kaynaklanır. Gerçekte iki uç arasında tedrici bir süreklilik bulunur. Bu eksende yaklaşımı ana hatlarıyla şöyle açıklayabiliriz:

\section{Enformatif Eylem ve Tasarımın Semantik, Estetik, İşlevsel Yönleri}

Tasarlayıcı imgeleme doğayı beşeri bir düzene sokmak, onu bir tasarım nesnesine dönüştürmek için ona tabi olduğu tekno-kültürel paradigmadan enformasyon aktarır. $\mathrm{Bu}$ düzenleyici, biçimlendirici, tasarlayıc1 etkinlik "enformatif eylem" olarak adlandırılabilir. George Simmel'in (2009: 331) kültürün özüne dair çözümlemesinde kullandığı "teleolojik müdahale" kavramı tam anlamıyla enformatif eylem kavramına denk gelir. Zira Simmel'e göre kültürleme şeylerin kendi doğal gelişimlerinin ötesinde bir kusursuzluğa eriştirildiği amaç yönelimli bir insan müdahalesidir. Enformatif eylem de bir teleolojik müdahale, kültürleme çabasıdır. Amacı doğal malzemeye insanların formel zihinsel örüntülerine ve anlam kozmolojilerine göre antropojenik bir form vermektir. Bu 
form verme işlemi semantik yorumlama, estetik izlenim oluşturma ve sembolik çağrışımlar üretme özelliklerini taşıdığı için iletişimsel bir süreçtir. Crilly, Moultie ve Clarkson'a (2004: 547-577) göre bu yönleriyle fiziksel nesnelerin tasarımı, belli bir ürünü işlevsel olarak imal etmek için olduğu kadar aynı zamanda o ürün aracılığıyla belli bir anlamı iletmek için de gerçekleştirilir. Bu yüzden zanaatçıların teknik düzenlemeleri ve ortaya koydukları tasarım nesneleri ile iletişimcilerin yöntemleri ve kurguladıkları metinler arasında fark bulunmaz. Hatta bizatihi tasarım nesnelerinin, zanaatçıların metinleri oldukları -veya iletişimcilerin metinler üreten zanaatçılar oldukları- söylenebilir. Bu yolla her bir tasarım nesnesinin formu, onu kullananlara işlevsel içeriklerinin yararlarının yanında kendisine enformasyon olarak yüklenen kültürel anlamları da dolayımlama özelliği gösterir. Haliyle tasarımın formu ve kodları yoğun biçimde tasarım nesnesini semantik, estetik ve işlevsel bir varlık haline dönüştüren eylemlerin beslendiği geniş bir kültürel artyöreye yaslanır. Bu artyöre yaygın kültürel teamülleri, kullanım alışkanlıklarını, uzlaşımları tasarım nesnesi üzerinde belirginleştirerek; sınırlayıcı, biçimlendirici ilkeler ve kurallar oluşturarak tasarım eylemini olumsal bir çerçeveye yerleştirir.

Resim, sinema gibi iletişimsel karakteri daha belirgin yüksek kültüre dair arı entelektüel uğraşılardan mimari ve gündelik yaşam nesnelerinin umumi endüstrilerine kadar her türden tasarım disiplini aynı kültürel yapının birbirleriyle ilintili, iç içe geçmiş estetik ve işlevsel boyutlarının yanında semantik yönlerini de yeniden üretir. $\mathrm{Bu}$ kültürel boyutların bütüncül etkisi her bir artefakt nesnenin fiziksel varoluşunda tecessüm eder. Buna binaen form, salt estetiğe veya işleve özgü bir olgu değildir. Semantik boyutları da içerimler. Estetiği, semantiği ve işlevi bir form içinde mümkün kılan şey birbirlerinden yalıtık kalmalarının mümkün olmadığ 1 bir enformasyonelliğin üçünü de taşımasıdır. Sözgelimi bir yelkenli teknenin formu estetik görünüm kadar zenginliğe veya tarihsel değerine vurgu yapan semantik çağrışımları ve su üzerinde yol alabilmesinin tekniğini yansıtan işlevsel çizgileri de yansıtır. Zira su üstünde hızla gidebilme (işlev), zenginlik (semantik) ve güzellik (estetik) arasında kurulan bu tarz teknoloji rüyaları ulaşım sistemlerine atfettiğimiz yaygın kültürel kodlarla, modern mitoslarla yakından ilişkilidir. Bu tür araçlar mutlak bir form olarak ulaşım işlevine yönelik değildirler. Bunlar aynı zamanda estetize edilmiş birer nesne, itibar öğesi, kullanım bilgisi ve yaşam tarzı taşıyıcılarıdır. Belli bir ulaşım aracına içkin anlama vakıf olmak için (zenginlik veya orta sınıf sadeliği, spor tutkusu ve macera gibi) sadece onun mekanik düzeneğini çözümlemek yeterli olmaz. Demir, ahşap, kauçuk ve çeşitli kimyasallardan oluşan ve hareket eden salt bir mekanik bileşik değil ulaşım hız ve verimliliğine, kullanım güvenliğine ve kurallarına, ulaşım sistemlerini düzenleyen otoritelerin talep ettiği norm ve kodlara, sosyal statülerin karşılık geldiği beğeni kültürlerine, değerleme ve yargılara göre teleolojik olarak tasarlanmış artefakt varlıklardır. Artefakt nesneler, bunları mümkün kılan kültürel artyörelerle zaruri ve 
sürekli bir bütünlük içindeki bireysel tasarlayıcı imgelemelerin dışavurumundan tezahür etmiştir.

\section{Tasarlayıcı İmgeleme ve Kültürel Etos}

Somut tasarımlar kültürel teamüller ve anlamlar ile nesneler dünyasının fiziksel elverişliliklerinin etkileştiği bir ağda meydana gelirler. Her bir yeni tekil artefakt olgu yüzeyde somut olarak bireysel girişim, keşifler, icatlar yoluyla toplumsal dünyaya kat1lıyormuş gibi görünse de ekolojik, tarihi ve kültürel kaynakları bakımından steril değildir. Kahraman mucitlerin veya sanatçıların konumları yaşadıkları toplumların tarihsel arka planından türeyen kalıplaşmış bilgi sistemlerinin, kültürel anlam ağlarının ve toplumsal/ekonomik etkileşimler şebekesinin kompozisyonunu oluşturduğu bir konjonktür üzerinde yükselen zirvelerdir. Homo faber kahramanlarımız yükselen dalgaların üzerindeki yetenekli sörfçülerdir. Bu bakımdan özgün gibi görünen artefakt olgular bile önemli ölçüde teknik, semantik ve estetik bir kültürel kompleksitenin imbiğinden çıkarlar.

Tasarlayıcı imgeleme vasıflı bir düşünme tarzıdır. Önemli ölçüde soyut ve materyal kültürün kolektif kaynaklarına, kültürün anlamlı sembollerine bağımlıdır. Aslında açık ve kamusal bir eylem özelliği gösteren, nesnel materyallerin amaçlı denetimini içeren düşünme, muhtemelen insanlar açısından temel niteliktedir. $\mathrm{Bu}$ açıdan yaşadığı olaylara, yöneldiği varlığa anlamlı bir yapı kazandırmaya odaklı tasarlayıcı düşünme tarzı da antropolojik açıdan temel bir özelliktir (Geertz, 1973: 45, 76). Tasarlayıcı imgeleme sınırsız bir hayal gücünün keyfiyetiyle değil tabi olduğu duygulanım ve söylem atmosferiyle sarmalanmıştır. Dolayısıyla muhtelif soyut iletişimsel kültür biçemlerinde, bir sinema filminde, müzik eserinde veya edebi metinde olduğu gibi, anlam ağlarını ve zihniyet dünyalarını, insanların yaşamlarının tonunu, karakterini ve niteliklerini, ahlaki ve estetik biçemlerini, ruhsal durumlarını yansıtan bir kültürel etos (Geertz, 1973: 127) tarafindan kuşatılmıştır.

$\mathrm{Bu}$ kültürel etos artefakt formlarda kaçınılmaz olarak tezahür eder. Dil, mantık, matematik, yerleşik değerler düzeneği, estetik yargılar gibi soyutlamaları aracılığıyla zihnin muhakeme yapabilmesi için bir "mümkün kılıcı" ama aynı anda "düzenleyici, sınırlayıcı bir filtre" olarak tasarım nesnelerinin ufkunu, estetik ve semantik çerçevesini belirler. Bu çerçeve, mekân ve kentsel çevre kullanımı, mimari, teknik araç gereç üretimi, güzel sanatlar gibi materyal kültür dünyasının bir hayli formel ve geleneksel, yerleşik entelektüel çıktılarıyla düşümdeşir. Zira bu sayede sözgelimi entelektüel düzeyde Art Nouveau, Bauhaus, Fonksiyonalizm, Expresyonizm gibi belirli bir mimari akımı ya da Selçuklu Şehri, Antik Yunan polisi gibi belirli bir tarihsel veya yerel kültürün mekân düzenlemesini ana figürleriyle ayırt etmek, onlara tekabül eden kültürel değer ve anlam şemalarını açığa çıkarmak, hangi sembolik, ayinsel, ideolojik veya mitik sistemden tezahür ettiklerini betimlemek mümkün olur.

Antropojenik dünya, tanınabilmesi ve anlamlı bir yapı arz etmesi için tekrarlı ve görece öngörülebilir örüntüler içinde basitleştirilmiştir. Örneğin materyal kültür alanlarının geometrik düzenlenmesi doğanın bir kültürel etosun elinden ve tasarım 
kodlarından geçerek artefakt varlıklara nasıl dönüştürüldügünün belirgin bir yönünü verir: El değmemiş tabiatta mükemmel ölçülerde daire, kare, dikdörtgenler prizmas1 gibi geometrik nesneler bulmak istisnadır. Rasyonalistlerin "tam anlamıyla doğru olan çizgiler, hiçbir yer işgal etmeyen noktalar, yetkin daire ve üçgenler benzeri matematiksel kendiliklerle deneyimde hiçbir zaman karş1laşılmaz" (West, 2013: 42-43) argümanı bütün gücü ile empirik doğa deneyimine rağmen kendini kabul ettirir, varlığa anlamını dayatır gibidir. Doğada kaotik veya fraktal biçimler/biçimsizlikler hâkim iken, insanlar kolaylıkla ayırt edilebilecek, algılanabilecek ve insan bilişinin tanımlama, örüntüleme kalıplarına denk düşen formlar üretme eğilimindedir. Geometri bir yandan bir nicelikler dünyası tasavvur ederek çizgiler ve çizim yoluyla bu dünyanın unsurlarını oluştururken, diğer yandan zihin dünyasında da mümkün ve zorunlu olarak kendini gösterir. Zihin burada, çok somut gerçeklik ve hakikati elinde tutar; geometrinin düşünülmüş cisimsel şekilleri ve yüzeyleri, noktaları ve çizgileri gerçekte insanın zihin dünyasındaki düzenleridir (Cassirer, 2011: 11). Özellikle Greko-Roman geleneği içinde insan bilişi artefakt yaşam alanlarını dış dünyanın algısı ve zihnin formel etkisinin senteziyle baskın olarak Öklidçi formlarla düzenlemiştir. Bilgi yazım yüzeyleri (kitaplar, kiosklar, bilgisayar ekranları, fotoğraf çerçeveleri, trafik bilgi panoları vb.) dikdörtgen şeklindedir. Yaşam mekânları (evler, bürolar vb.) ağırlıklı olarak kübik veya prizma bloklar biçimindedir. Roma idealinin taşıdığı kent formu bölgesel yöneticileri tarafından bakir yerleşim alanlarına, tapınakları ve forumu, sarnıcı, tiyatrosu ve hamamları ile düzenli blok ve caddelerden oluşan bilinen kare veya dikdörtgenel 1zgara modeline göre kurulmuştur. Benzer biçimde şehirlerin geometrik biçimi hakkındaki Çin dünya görüşü de -veya kültürel etosu da- üç bin yılı aşkın bir zaman evvelinden şekillenmiş ve değişmeden kalmıştır: Çin'in Chang'an, Hangçov gibi İmparatorluk şehirleri geometrik kusursuzluk sergilemek zorundaydı. Geleneğe göre şehir, Çin inanışında yer alan, merkezinde Cennet'in oğlunu barındıran kare şeklindeki evrenin fiziki bir beyanı olacak şekilde, dörtkenarlı inşa edilmeli ve tam olarak kuzey-güney ekseninde yönlenmiş duvarlarla çevrili olmalıydı. Her duvar ve çeperindeki bölge güneşle kurduğu açıya uygun bir mevsimle bağdaştırılırdı; doğu ilkbahar, güney yaz, batı sonbahar, kuzey ise kış mevsimi ile... Çin imparatorluk şehirleri siyasi içerikli hanedan mücadelelerinin baskısı altında Greko-Roman dünyasıyla kıyaslandığında taş fakiri bir coğrafyada tuğla ve ahşap malzemeyle inşa edildikleri için zamana veya toplumsal olaylara dayanamayarak sürekli yıkılmış olsa da bunları inşa eden görüş parşömen, ipek ve pirinç kâğıdı parçaları ya da yetkili kişilerin zihinlerindeki yazı ve çizimler olarak muhafaza edilmişti. İmparatorluk şehrinin geometrik ve formel ideali gerçeğinden daha dayanıklıydı (Reader, 2007: 99-100, 103). Birçok kültürün tasarım geleneğinde oval, kavisli ve yoğun organik formlar da tercih edilmişti. Ama oval veya kavisli çizgilerin hâkim olduğu bu geleneklerde de tanınabilir kusursuz geometrik formlar hakimdir. Arabesque bu açıdan tipiktir. Bir başka örnek olarak yoğun biçimli zarif dekoratif süslemelerin ön plana çıktığı, doğal, kıvrımların ve 
bitkisel desenlerin sıklıkla kullanıldığı Art Nouveau gibi sanat akımlarına bağlı düzenlemeler bile son kertede ritmi, tekrarı ve vurguları olan anlamı ayrıştırılabilir düzenlemelere sahip geometrik kompozisyonlar sunarlar. Hangisi olursa olsun geometrik tasarım formları tabi oldukları kültürel etosun, akım, töre veya geleneklerin soyutlama şemalarının estetik ve semantik filtreleri içinde basitleştirilerek harmanlanmıştır.

\section{E. Tasarımın Tekno-Kültürel Paradigması}

Takip ettiğimiz perspektif ideadan maddeye veya maddeden ideaya doğru tek yönlü bir akış ortaya koymayı amaçlamaz. Ama Şekil 1'den izlenebileceği üzere tasarlayıcı imgelemenin tasarım nesnesine yönelik teleolojik müdahalesini (enformatif eylemi) merkeze alır. Tasavvurların olumsal esnekliğinden dolayı kültürün soyut veçhelerinin tasarım nesnesi üzerinde göreli bir yansıması bulunur. Diğer yandan nesnel dünya ile toplumsal ekolojinin zorunlu kıldığı rasyonel kullanım biçimlerinin etkisine de daha önce vurgu yapılmıştı. Böylece analizin genel yaklaşımından tasarımın tekno-kültür alanının, coğrafi ve toplumsal dünyanın salt nesnel yapılarının birebir yansıması olmadığı sonucuna varırız. Zira kültürün esnek yapısı böylesi bir objektif yansıtma mekanizmasını mümkün kılmaz (Sarıbay ve Öğün, 2013: 80), onu göreli olarak dönüştürür. Materyal kültür alanı ile kültürel etosun yeknesak biçimde kristalize olduğu tedrici bir çeşitlilik akla daha yatkındır. Sözgelimi iklim, konutların biçim ve yapılaşma zihniyeti veya toprak yapısı, tarım aletlerinin biçimi ve tarımsal üretim gelenekleri birer holistik kompleks oluştururlar. Ama benzer fiziksel elverişlilikler içinde bile olsalar farklı kültür dünyalarının aynı tuvali görece farklı desenlerle doldurduğu bilinmektedir.

Şüphesiz tasarımın mümkün olması, tasarım projesinin hayata geçirilmesi için toplumsal ekolojinin sunduğu elverişlilikler tarafindan çerçevelenmiş endüstriyel ve teknik altyapıların, kaynakların varlığının zorunluluğunun yanında, bu altyapı ve kaynakların tahsisi noktasında da toplumdaki sembolik etkileşimler, iktidar ilişkileri ve ekonomik rasyonalite belirgin bir rol oynar. Süreç belli bir kültürel kompleksite içinde yürüyen iktidar kaynaklarının toplumsal dağılımına, inançlara, büyü, mit, bilim ve hakikat kavrayışlarına bulaşıktır. Örneğin Ayasofya, form ve hacmi içinde ruhaniyeti olduğu kadar mühendislik becerileri ile siyasal gücü ve egemenliği de eritir. "Kubbesiyle ilahi gücü, sütun ve duvarlarıyla da bu tanrısallığa hizmet eden beşeri gücü temsil eden bu yapı din ile siyaseti sembolik olarak birleştirir" (Cündioğlu, 2012: 39). Bu eksende tasarımın dayandığı kültürel etos ile materyal kültür simbiyotik ve organik bir bütünlük içindedir. Bu nedenle tasarımın kültürel dinamiği birbirini etkileyen ortak anlam ve estetik ağlarının, endüstriyel ve fiziksel elverişliliklerin, sembolik iktidar biçimlerinin içinde tümleşik bir yapıda organize olan tasarım pratiklerinden türer. Her yeni tasarım nesnesi hem tasarlayıcı imgelemenin yorumlama pratikleri üzerinden geribildirim yaparak kültürel etosa yayılır, tasarım geleneklerini pekiştirir (kültürün yeniden üretimi) veya dönüştürür (kültürel değişme) hem de makro ölçekte tasarımın soyut kültürel kaynakları (kültürel etos) ile maddi koşulları (materyal kültür) üzerinde birikir ve toplumsal konjonktüre yığılır. Bu konjonktürel yığılmanın yekûnunun 
imbiğinden çıkan endüstriyel-kültürel uyarlama biçemleri tasarım etkinliklerinin vuku bulduğu toplumun tekno-kültürel paradigmasını verir.

\section{F. Tekniklerin ve Yapının Yayılımı}

Tekno-kültürel paradigma kapalı ve yalıtık değil dış çeperlerinden gelen kültürel difüzyona açıktır. Difüzyon yabancı bilginin, normların, anlam şemalarının ve değerlerin değişik formlarının materyal kültür unsurlarıyla birlikte içeriye geçişini sağlar. Tasarımlar ve teknikler farklı kültürler arasından geçerken hâlihazırda orijin olan kültürün bir yapıntısı olduklarından o kültürün bilgi rejimlerini ve geleneklerini de belirli ölçülerde aktararak ilerlerler. Kökenlendikleri toplumların insan ve tabiat üzerindeki otantik denetim tercih ve eğilimlerinden kaynaklanan özgül şartlara bağlı olarak belli tarz, norm ve değerleri, hatta güç, iktidar ilişkilerini de bünyesinde barındırırlar. Orijinal kültürel içeriğin estetik ve semantik kodlarını miras alarak yeni kültürel kozmosa nispi dönüşümleriyle yayilırlar.

"Bunun en kesin örneği Batı teknolojisinin girdiği her topluma liberal-kapitalist bir hayat anlayışının da girişidir. Çünkü objektif gerçekler sanılan Batı teknolojisi öncelikle Batı Avrupa toplumlarının bilgi gelişmesinin bir sonucudur. [...] Her somutlaşmış (süjeden kopmuş) kültür verisi gibi teknik bilgiler de aktarılabilir. Fakat her haliyle değil; ondan yararlanmanın belli kuralları vardır. [...] Onu ortaya çıkaran dünya görüşünün, toplumsal gelişmenin de kavranması gerekir" (Aydın, 2013: 74).

Sözgelimi modern ulaştırma sistemlerinin kaynak ülkelerden diğer toplumlara transferi bu sistemlerin bütün altyapısının (yollar, yakıt lojistik sistemleri vs.), ticari ilişkiler ağının (otomotiv firmaları, satış bayileri, reklamlar gibi) ve otomotiv kültürüne özgü her ne varsa (kullanım normları, trafik kuralları, sinema filmleri ve bilgisayar oyunları gibi) her şeyin belli ölçülerde kopyalanmasını da gerektirmiştir. Bütün bu olgular içerideki kültürel sentezlemelerle tasarım pratiklerinin tabi olduğu konjonktürel, çevrimsel alanı göreli etkilerle dönüştürürler.

Diğer yandan çoğu durumda bunlar bütün monoblok yükleri ile başka kültürlere olduğu gibi yansımazlar. Çünkü bu fazda yerel kültürel süzgeçler, anlam şemaları ve yerel bilgi, daha genel manada yerel kültürel etosun etkisi, yerel geleneğin direnci her yerde özgün dinamikleriyle kendini vurgular. Tasarlayıcı soyutlamaların olumsal esnekliği ile fizik dünya arasındaki zorunlu uyarlanma ilişkileri tekniklerin yayılımında da orijinalin standartlarından sapma eğilimleriyle birlikte işler. Sözgelimi taşıma araçlarında Bavyera sadeliği ile Pakistan mistik kamyon süslemesi iki farklı toplumsal örüntü işleme ve estetik uygulama biçiminin çarpıcı birer görüntüsünü verirler. Yerel kültürel etos yabancı menşeili artefakt varlığı yerel semantik ve estetik okumalara maruz bırakır ve uygulamada göreli olarak dönüştürür. 


\section{SONUÇ}

Genel analiz çerçevemiz, tasarlama becerilerindeki olumsal semantik esnekliği ve zengin materyal kültür örüntüleri üretebilme koşullarını formel bir şemada betimlemektedir. Tasarımın kültürel dinamiğini bölüntüsüz bir etkileşim dizgesi içinde tanımlamakta; toplumları sarmalayan ekolojik koşullar, üretim yoluyla genişleyen materyal kültürel envanter ile teknik üretim pratiklerine uygulanabilir kültürel rejimleri ve gelenekleri kapsayan geçişsiz ve holistik bir tekno-kültürel yapı öngörmektedir. Bu yapının materyal kültür görünümü teknokültürel yapılara içerilmiş, toplumsal etkileşimlerin dokusundan türeyen nesnel bir artefakt düzen olarak kavramlaştırılmıştır. Diğer yandan kültürel artefaktların ussal, semantik ve estetik bir öznel vektörü daha bulunmaktadır. Bu öznel vektör tasarlayıcı aktörlerin (zanaatçıların) enformatif, iletişimsel imgeleme becerilerinin, yerleşik alışkanlıklarının bir yekûnu olarak tasarım gelenekleri ve belli bir kültürel düzen üretebilme niteliğiyle bağlantılıdır. Pierre Bourdieu'nün (2005: 129, 143, 158) yeniden üretim döngüsü olarak adlandırdığı perspektifinden bir ifadeyle tasarımcıların yerleşik alışkanlıkları, bir durumdan diğerine aktarılabilen dayanıklı eğilimleri, toplumsal yapılar tarafından yapılandırılmış oldukları kadar (nesnel toplumsal kategori) bu yapıları yapılandırırlar da (öznel toplumsal kategori). Bu yönüyle artefakt dünyanın tasarımı, materyal kültürün nesnel ilişki ağlarından olduğu kadar tabi oldukları kültürel etos içindeki aktörlerin anlam kozmolojilerinden de türemektedir. Bütün bu etkileşim çerçevesi işlevsel, semantik ve estetik formlara bürünerek tasarımların ruhuna nüfuz etmekte, artefakt nesnelerde somutlaşmakta ve dönüşlü olarak tasarım geleneklerini, estetik dünyalarını, toplumsal ve kültürel anlamlarını yeniden inşa etmektedir.

Kuşkusuz her teorik tasavvurda olduğu gibi burada sunulan yaklaşım da işlemsel bir soyutlamadır. Öncelikle oluşturulan formel çerçevenin ampirik analize açılması gerekmektedir. Ampirik analiz ise çok yönlü bir çalışma olmak durumundadır. Artefakt dünyanın kentler, teknik aygitlar, mimari tasarımlar, sanat eserleri gibi çok farklı görünümleri bulunmaktadır. Materyal kültür alanındaki çeşitlilik içinden alınacak verilerin çözümlenmesiyle formel düzeyde sunulan analiz çerçevesinin rötuşlanması mümkündür. Bu eksende çalışma kapsamlı bir dizi araştırma projesine kapı aralayabilir niteliktedir. İkinci olarak yeni okumalarla iletişim bilimlerinden felsefeye, kültürel antropolojiden sosyolojiye kadar farklı ilgilere göre oluşturulmuş literatürün tasarım dünyalarını kuramlaştırma tarzlarının izdüşümleri, farkl1 perspektiflerin örtüşen zemini netleştirilerek yaklaşım interdisipliner bir kapsamda genişletilebilir. Bu iki muhtemel çizgide çalışmanın tasarımın kültürel işleyişine ilişkin temel kavramları bir araya getiren, ilişkilendiren ve aralarındaki dinamikleri betimlemeyi amaçlayan şematik çerçevesinin yeni araştırma ve sorgulamaları harekete geçirir nitelikte olduğu umudu taşınmaktadır.

\section{AÇIKLAMALAR}

Maurice Duverger (t.y.: 52) "toplumsal ekoloji” kavramını biyolojik ekoloji kavramından farklı olarak doğal kaynaklar, iklim, toplumlar arasındaki 
konum yakınlığı ve ilişki yoğunluğu gibi coğrafi koşulların toplumsal etkileşimler üzerinde neden olduğu etkileri betimlemek üzere kullanır.

Marshall ve Pengelly (2005: 25-33) "tekno-kültürel paradigma" kavramını Christopher Freeman'ın, "tekno-ekonomik paradigma" kavramlaştırmasından hareketle türetmişlerdir. Tekno-ekonomik paradigma yalnızca bir dizi üzün ya da sistemde değil üretimdeki bütün dinamiklerde görülen birbiriyle bağlantılı yapıları ima eder (Castells, 2008: 88-89). Buradan hareketle tekno-kültürel paradigma kavramı tasarım geleneklerine yön veren, sınırlar çeken; belirli bir semantik ve estetik çerçeve içinde onları mümkün kılan biçimlendirici bir kültürel ve endüstriyel epistemolojik art alanı ima eder.

\section{KAYNAKÇA}

Arendt, Hannah (1998). Human Condition. London: the University of Chicago Press, Ltd.

Aydın, Mustafa (2013). Bilgi Sosyolojisi. İstanbul: Açılımkitap.

Batur, Tekin (2012). Zanaattan Sanata Tarihsel Süreçte Resim. İstanbul: Cinius Yayınları.

Bourdieu, Pierre (2005). Pratik Nedenler: Eylem Kuramı Üzerine. Çev. Hülya Uğur Tanrı̈ver. İstanbul: Hil Yayın.

Cassirer, Ernst (2011). Sembol Kavramının Doğası. Çev. Milay Köktürk. Ankara: Hece Yayınları.

Castells, Manuel (2008). Enformasyon Çă̆l: Ekonomi ve Kültür, Birinci Cilt. İstanbul: Bilgi Üniversitesi Yayınlar1.

Crilly, Nathan, James Moltie, P. John Clarkson (2004). "Seeing Things: Consumer Response to the Visual Domain in Product Design". Design Studies 25 (6): 547-577.

Cündioğlu, Dücane (2012). Mimarlı ve Felsefe. İstanbul: Kapı Yayınları.

Dimitrov, Vladimir, Robert Woog (1997). "Studying Social Complexity: From Soft to Virtual Systems Methodology". Complex Systems 11: 501-509.

Duverger, Maurice (t.y.). Siyaset Sosyolojisi. Çev. Şirin Tekeli. İstanbul: Varlık Yayınları.

Epstein, Steven (2008). "Culture and Science/Technology: Rethinking Knowledge, Power, Materiality, and Nature". the ANNALS of the American Academy of Political and Social Science. 619: 165-182.

Geertz, Clifford (1973). the Interpretation of Cultures: Selected Essays. New York: Basic Books, Inc., Publishers.

Güvenç, Bozkurt (1984). İnsan ve Kültür. İstanbul: Remzi Kitabevi.

Habermas, Jürgen (1993). İdeoloji Olarak Teknik ve Bilim. Çev. Mustafa Tüzel. İstanbul: YKY.

Kiel, L. Douglas (2005). Knowledge Management, Organizational Intelligence and Learning, And Complexity. http://www.eolss.net/ebooks/Sample\%20Chapters/C15/E1-29.pdf. UNESCOEOLSS Sample Chapter.

Kottak, Conrad Phillip (2002). Antropoloji: İnsan Çeşitliliğine Bir Bakış. Çev. Erhan G. Ersoy. Ankara: Ütopya Yayınları.

Kuhn, Thomas S. (2008). Bilimsel Devrimlerin Yapısı. Çev. Nilüfer Kuyaş. İstanbul: Kırmızı Yayınları.

Lévi-Strauss, Claude (2013). Irk, Kültür ve Tarih. Çev. Reha Erdem, Arzu Oyacığlu, Haldun Bayrı, Işı Ergüden. İstanbul: Metis Yayınları.

Luhmann, Niklas (2000). the Reality of the Mass Media. Translated by Kathleen Cross. California: Stanford University Press.

Malinowski, Bronislaw (2000). Büyü, Bilim ve Din. Çev. Saadet Özkal. İstanbul: Kabalcı Yayınevi.

Marshall, John, Jon Pengelly (2005). "Perimeters, Boundaries and Borders: New Dimensions of Design in the Convergent Fields of Sculpture, Industrial Design and Architecture". Crossing Design Boundaries. Edited by Paul Rodgers, Libby Brodhurst and Duncan Hepburn. London: Taylor and Francis. 
McQuail, Dennis (1984). Aspects of Modern Sociology: Communication. New York: Longman Group Ltd.

Moles, Abraham A. (1995). Kültürün Toplumsal Dinamiği. Çev. Nuri Bilgin. İzmir: Ege Üniversitesi Edebiyat Fakültesi Yayınları.

Reader, John (2007). Şehirler. Çev. Fatine Bahar Kalıdă̆. İstanbul: YKY.

Ritzer, George (2012). Modern Sosyoloji Kuramları. Çev. Himmet Hülür. Ankara: De Ki.

Rogers, Everett M. (1983). Diffusion of Innovations. New York: the Free Press.

Rosengren, Karl Erik (1994). "Culture, Media and Society: Agency and Structure, Continuity and Change". Media Effects and Beyond: Culture, Socialization and Lifestyles. Edited by Karl Eric Rosengren. London: Routledge.

Sarıbay, Ali Yaşar, Süleyman Seyfi Öğün (2013). Politikbilim. Bursa: Sentez Yayıncılık.

Sahlins, Marshall (2012). Batı'nın İnsan Doğası Yanılsaması. Çev. Emine Ayhan, Zeynep Demirsü. İstanbul: Bgst Yayınları.

Shannon, Claude Elwood, Warren Weaver (1948). "the Mathematical Theory of Communication". the Bell System Technical Journal 27: 379-423.

Simmel, George (2009). Bireysellik ve Kültür. Çev. Tuncay Birkan. İstanbul: Metis Yayınları.

Tatlıcan, Ümit (2011). Sosyoloji ve Sosyal Teori Yazıları, Bursa: Sentez Yayıncılık.

Weiner, Norbert (1989). the Human Use of Human Beings: Cybernetics and Society. London: Free Association Books.

West, David (2013). Klta Avrupası Felsefesine Giriş: Rousseau, Kant ve Hegel'den Foucault ve Derrida'ya. Çev. Ahmet Cevizci. İstanbul: Paradigma Yayıncılık.

Williams, Raymond (1983). Keywords a Vocabulary of Culture and Society. New York: Oxford University Press.

\section{SUMMARY}

This study focuses on cultural and material factors having a part in formation of design styles. The study approaches the material culture as a constructed entity in a communicational manner within a techno-cultural paradigm. Theoretical framework formed for the study is based on a postulate that design effort is not only an individual profession or a genius creation and but also a multidimensional result which passes through the complex filters of a natural, socio-cultural and economic set.

Basic hypothesis of the study is that there is a monolithic complexity between culture and nature, abstract and material sides of culture instead of a hierarchical, discriminative or dualistic positioning. The world of artefact objects equipping the social world is built within this complex system. Cultural codes of design retrieve their stylistic data through cultural ethos in which the conceiver imagination arouse. Material entities of design arise in the accumulation of material culture that makes the design possible and in the social ecology that covers the conceiver imagination.

Every cultural ethos influences technical traditions and ways of economical utilization of the design object by presenting a system of combined vessels formed by prominent aesthetical styles, semantic orders, values, norms, epistemological formulas, power relations. Productivity and effectiveness of a certain cultural ethos towards the design effort is also depended upon the extent of compatibleness with geographical affordances, utilizable resources and nomological principles of how nature works. The whole framework composes the techno-cultural paradigm of the 
relevant society or of the relevant era with the osmosis between material culture and design traditions.

Moreover, the whole structure is also influenced by the foreign norms, values, epistemes, products, means of production, fabricated or raw materials, which physically or culturally diffuse inside through external cultural environment. Input of knowledge, value and outcomes of the foreign design systems affect the composition of internal design ecosystem significantly. However this effect seldom spreads as an essential imitation, but generally it is a synthesis of local cultural ethos and local social ecology in various extents in quality.

This entire collective framework influences the structure of particular and individual design effort. Conceiver imagination operates an informational process while he transmits his knowledge, meanings and abilities to the design object in this ambience of techno-cultural paradigm. Hence, this process makes the design action as a communicational action. The design object is exposed to a threedimensional creation that contains a functional aspect reflecting usefulness, a semantic aspect informing about its cultural meanings and its core nature and an aesthetical aspect aimed to be attractive for senses and tastes. Creation is an informing process since creation is a teleological intervention to the material essence of design objects to manipulate its natural dispositions as regard to anthropomorphic concerns. In terms of conceiver imagination, the design object is an information transfer with reduced noise.

At the end of the process, each design object transforms the design codes of the cultural ethos through small additions made to the cultural codes of the design. Ideas emerged from the interaction between designer and design process accumulate within the experience of conceiver imagination. They are reflected to the collective phase by time. These processes renew and change the physical environment of social life. The conjunctural accumulation of these feedback processes keeps the dominant techno-cultural paradigm within that community in a long term evolution. 